\title{
Isothermal and thermomechanical fatigue interaction in fatigue crack propagation behavior of a low-carbon nitrogen-controlled 316 stainless steel
}

\author{
Yasuhiro Yamazaki \\ Chiba University, Japan \\ Y.yamazaki@chiba-u.jp
}

\begin{abstract}
In this work, the effect of superimposing of isothermal Low Cycle Fatigue (LCF) loading to the thermomechanical (TMF) fatigue loading on the short crack propagation behavior of low-carbon nitrogen-controlled 316 stainless steel is investigated. The experimental results indicate that the crack propagation path depends on the loading condition; cracks initiate and propagate at grain boundary perpendicular to the loading axis (intergranular mode), which is a relatively weak region, under the in-phase TMF loading and the LCF loading at high temperature. On the other hand, cracks initiate by the transgranular mode under the out-of-phase TMF loading and the LCF loading at middle temperature. The crack growth rate is also affected by the microstructure, i.e., the intergranular crack exhibits higher crack growth rate compared with the transgranular crack. In addition, the crack growth rate is accelerated by the superimposing of the isothermal LCF loading to the TMF loading. The crack growth rate can be predicted according to the summation law of crack growth behavior based on the fatigue J-integral approach taking into account the crack propagation path.
\end{abstract}

KEYWORDS. Crack growth behavior; Short fatigue crack; Thermomechanical fatigue, Low cycle fatigue

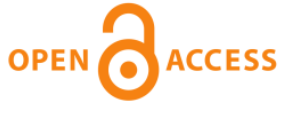

Citation: Yamazaki, Y., Isothermal and thermomechanical fatigue interaction in fatigue crack propagation behavior of a lowcarbon nitrogen-controlled 316 stainless steel, Frattura ed Integrità Strutturale, 48 (2019) 2633.

Received: 27.11.2018

Accepted: 07.01.2019

Published: 01.04.2019

Copyright: (C) 2019 This is an open access article under the terms of the CC-BY 4.0, which permits unrestricted use, distribution, and reproduction in any medium, provided the original author and source are credited.

\section{INTRODUCTION}

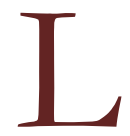

ow-carbon nitrogen-controlled 316 stainless steel (316FR) was developed as a structural material for a fast breeder reactor (FBR) plant [1-3]. The characteristics of high-temperature strength, such as the creep strength, have been investigated to apply 316FR to the FBR with high reliability [2-4]. In addition, failure due to creep-fatigue and thermomechanical fatigue (TMF) are critical issues that affect the design and reliability of the primary cooling piping because it undergoes cyclic thermal stress due to the start-up and shut-down of the reactor. Since the major part of the component life consists of the crack propagation process in LCF situations, an assessment of the naturally initiated fatigue 
crack growth is required for the design of components at high-temperature. Therefore, the fatigue crack propagation behaviors and the fatigue strength have been widely investigated under LCF, creep-fatigue and TMF conditions [5-15]. In the high-temperature components, the high-cycle fatigue (HCF) and the low-cycle fatigue (LCF) loadings are often superimposed on TMF loading. The superimposition of HCF or LCF loadings on the TMF loading may lead to lifetime reduction, as recently reported in Refs. [16-20]. The large value of TMF (and also LCF) leads to early fatigue crack nucleation compared with that of HCF. Therefore, the lifetime of components subjected to TMF is mainly controlled by the propagation process of the naturally-initiated small cracks. The fatigue crack generated by the main TMF loading might be accelerated by HCF/LCF loading even if the amplitude of HCF/LCF loading is smaller than that of TMF loading.

Based on the abovementioned background, this study deals with how naturally-initiated cracks on smooth specimen surfaces (made of 316FR) propagate under TMF loading combined with isothermal LCF loading. The influence of superimposition of LCF loading on the TMF loading is discussed using the J-integral approach, taking into account the crack propagation path.

\section{EXPERIMENTAL PROCEDURES}

he material tested in this study is a low-carbon nitrogen-controlled 316 stainless steel (316FR) plate manufactured by hot-rolling. The chemical composition of the tested material is $0.009 \mathrm{C}-0.55 \mathrm{Si}-0.84 \mathrm{Mn}-0.024 \mathrm{P}-0.007 \mathrm{~S}-11.25 \mathrm{Ni}-$ 17.0Cr-2.11Mo- $0.0751 \mathrm{~N}$ (mass \%). The solution heat treatment was given by keeping the plate at $1050{ }^{\circ} \mathrm{C}$ for 30 min followed by water quenching. Additional heat treatment was applied at $1250^{\circ} \mathrm{C}$ for $16 \mathrm{~h}$ before the hot-rolling process to suppress carbide precipitation by homogenizing the chromium distribution. A solid cylindrical smooth specimen with a diameter of $6 \mathrm{~mm}$ and gage section with a length of $16 \mathrm{~mm}$ was used to study the crack propagation behavior. The surfaces of all specimens were mechanically polished to mirror surface using alumina powders before and after the tests to remove machining marks and the oxide film. The observations and measurements of crack growth behavior were conducted by periodically replicating the specimen surface by using an acetyl cellulose film after cooling to room temperature.

The crack growth tests were performed under the following conditions.

TMF loading (IP, OP): in-phase (IP) and out-of-phase TMF loading.

combined in-phase TMF and LCF loading (IPC02, IPC04): 10 cycles of the isothermal-LCF loadings were superimposed on the primary IP cycle at the maximum temperature. The mechanical strain ranges of the superimposed LCF loading were $0.2 \%$ (IPC02) or $0.4 \%$ (IPC04).

isothermal LCF loading (CC1, CC2, PP): The isothermal-LCF loading at the maximum temperature (CC2, CC1) or the middle temperature (PP) of the TMF.

The test conditions are summarized in Table 1.

\begin{tabular}{|c|c|c|c|c|c|c|c|c|}
\hline & & OP & IP & IPC02 & IPC04 & $\mathrm{CC} 2$ & CC1 & $\mathrm{PP}$ \\
\hline \multirow{5}{*}{ Main cycle } & Temperature $\left[{ }^{\circ} \mathrm{C}\right]$ & \multicolumn{4}{|c|}{ Max.: 650, Min.: 290} & \multicolumn{2}{|c|}{650} & 470 \\
\hline & Strain range $[-]$ & \multicolumn{7}{|c|}{$0.6 \%$} \\
\hline & Strain rate $[1 / \mathrm{s}]$ & \multicolumn{4}{|c|}{$0.0025 \%$} & \multicolumn{3}{|c|}{$0.01 \%$} \\
\hline & Strain ratio [-] & \multicolumn{7}{|c|}{-1} \\
\hline & Phase angle $\left[^{\circ}\right]$ & 180 & & 0 & & - & - & - \\
\hline \multirow{4}{*}{$\begin{array}{l}\text { Superimposed } \\
\text { cycle }\end{array}$} & Temperature $\left[{ }^{\circ} \mathrm{C}\right]$ & - & - & \multicolumn{2}{|c|}{650} & - & - & - \\
\hline & Strain range [-] & - & - & $0.2 \%$ & $0.4 \%$ & - & - & - \\
\hline & Strain rate $[1 / \mathrm{s}]$ & - & - & \multicolumn{2}{|c|}{$0.025 \%$} & - & - & - \\
\hline & Strain ratio [-] & - & - & $1 / 3$ & $-1 / 3$ & - & - & - \\
\hline
\end{tabular}

Table 1: Test conditions employed in the experimental campaign 
All tests were performed under strain-controlled conditions by means of the TMF testing machine. A triangle waveform was used for both mechanical and thermal cycling. The total strain as the control signal was calculated by adding thermal strain (recorded previously as a function of temperature) to the mechanical strain.

\section{RESULTS AND DISCUSSIONS}

\section{Macroscopic stress-strain response}

$\mathrm{F}$ ig. 1 shows typical hysteresis loops observed during the experimental tests. As shown in Fig. 1(a) and (d), the IP and OP hysteresis loops were asymmetric as a result of temperature dependence on the deformation resistance of 316FR steel. The magnitudes of mean stress were less than $10 \%$ of the maximum stress although the mean stresses were negative in IP and positive in OP. The stress amplitude was comparable in both hysteresis loops for IP and OP, and both loops were symmetrical about the origin. In contrast, hysteresis loops were symmetric under the LCF conditions, as shown in Figs. 1(e), (f) and (g). Figs. 1(b) and (c) show that the main TMF loops of IPC02 and IPC04 were also asymmetric, and had almost the same shape as the IP loop. However, their stress ranges were smaller than those of IP and were almost comparable to those of CC1 and CC2 conditions. These results suggest that the stress-strain response of the main TMF cycle can be affected by the sub-LCF cycles. The sub-LCF loop of IPC04 had almost the same shape as the CC1 and CC2 loops. Inelastic deformation occurred during the sub-LCF cycle of IPC04 (Fig. 1(c)). No inelastic deformation occurred in the sub-LCF loop of IPC02, as shown in Fig. 1(b).

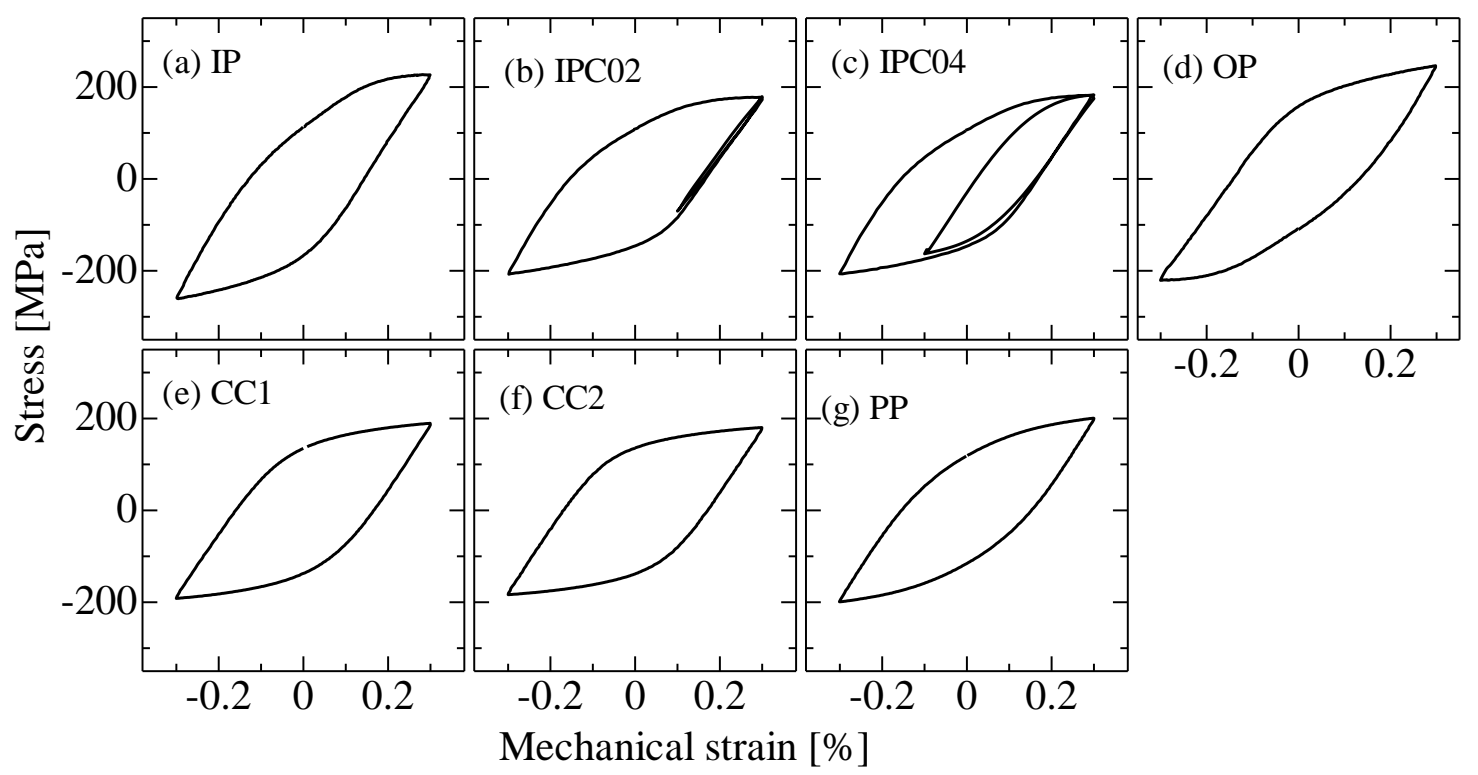

Figure 1: Stress-strain hysteresis loops observed during different test conditions: (a) IP, (b) IPC02, (c) IPC04, (d) OP, (e) CC1, (f) CC2 and (g) PP.

\section{Crack propagation behavior}

Typical fatigue cracks initiated by means of TMF and isothermal LCF loadings are shown in Fig. 2 and the mode of crack propagation is summarized in Table 2 . The results indicate that the initiation and propagation morphologies of naturally initiated fatigue crack are sensitive to the microstructure and the test temperature. Under IP, IPC02, IPC04, CC1 and CC2 conditions, where the tensile loading is applied at high temperature, the cracks initiated and propagated at grain boundary perpendicular to the loading axis. The grain boundary might be a relatively weak region at elevated temperature. On the other hand, under OP and PP conditions, where the tensile loading is applied at a lower temperature, the cracks initiated and propagated by the transgranular mode.

Fig. 3 shows the fatigue crack growth rates under the isothermal LCF loading correlated with the fatigue J-integral range, $\Delta J_{\mathrm{f}}$. In particular, the value of $\Delta J_{\mathrm{f}}$ for surface short crack is evaluated from the following equation [21, 22]:

$$
\Delta J_{f}=F^{2}\left\{\pi \Delta \sigma \Delta \varepsilon_{e}+f\left(n_{f}\right) \Delta \sigma \Delta \varepsilon_{p}\right\} a
$$


where $\Delta \sigma$ is the stress range, $\Delta \varepsilon_{\mathrm{e}}$ and $\Delta \varepsilon_{\mathrm{p}}$ are the elastic and plastic strain range, respectively, and $a$ is the half crack length. In this study, the total crack length, $2 a$, is defined as the crack length projected on the plane perpendicular to the load axis. Morever $n_{\mathrm{f}}$ is the cyclic hardening exponent $\left(n_{\mathrm{f}}=0.304\right.$ for isothermal LCF loading). $F$ and $f\left(n_{\mathrm{f}}\right)$ are given by:

$$
F=\frac{1.12}{\left(1+1.47 \lambda^{1.65}\right) \sqrt{\lambda}} \text { and } \quad f\left(n_{f}\right)=\frac{3.85\left(1-n_{f}\right)}{\sqrt{n_{f}}+\pi n_{f}}
$$

where $\lambda$ is the ratio of the crack depth and the surface crack half-length $(\lambda=0.84$ obtained from the fracture surface). For comparison, the fatigue crack growth curve of physically long crack obtained by using Compact-Tension (CT) and CenterCracked-Tension (CCT) specimens is also shown in Fig. 3 [5]. The growth rates of naturally initiated short cracks are higher than those of the physically long cracks at a given $\Delta J_{\mathrm{f}}$. This experimental evidence indicates the importance of the investigation of naturally initiated short crack growth behavior since the information on the basis of a physically long crack growth rate provides a dangerous evaluation of the reliability to real components.

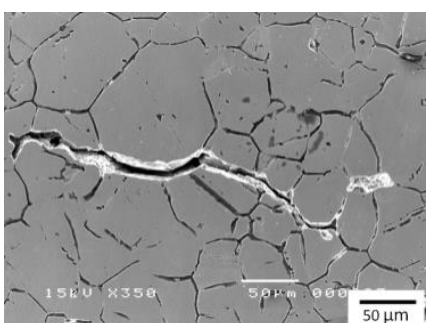

(a) IP

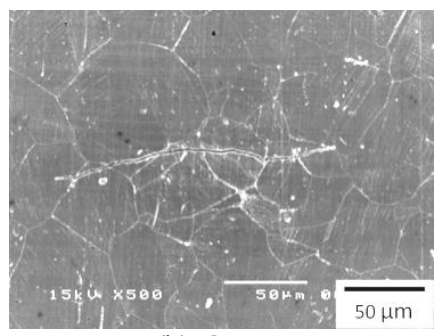

(b) OP

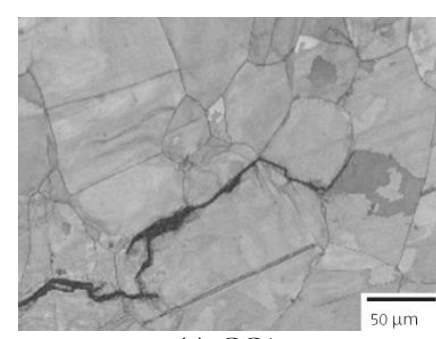

(c) CC1

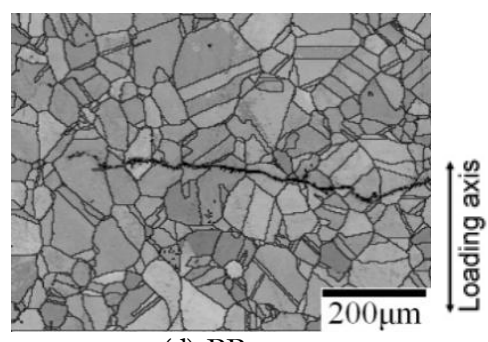

(d) PP

Figure 2: Typical fatigue cracks on the specimen surface: (a) IP, (b) OP, (c) CC1 and (d) PP.

\begin{tabular}{cccc|cc}
\hline IP & IPC02 & IPC04 & CC1 & CC2 & OP \\
\multicolumn{3}{c|}{ Intergranular mode } & & Transgranular mode \\
\hline
\end{tabular}

Table 2: Propagation modes of fatigue cracks initiated on the specimen surface.

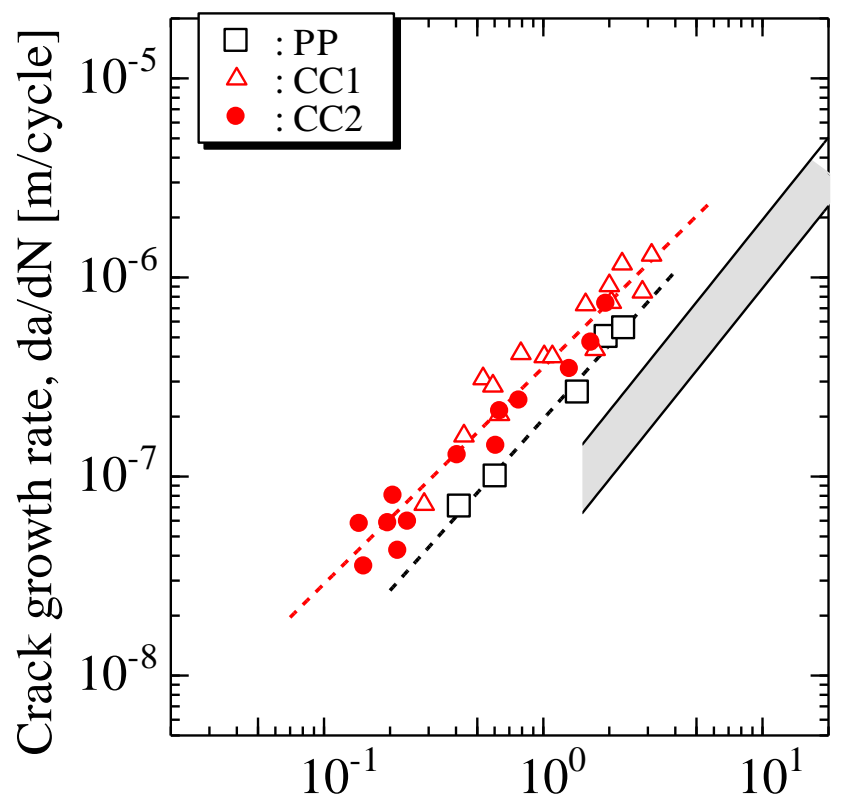

Fatigue J-integral range, $\Delta \mathrm{J}_{\mathrm{f}}[\mathrm{kN} / \mathrm{m}]$

Figure 3: Fatigue crack growth rates under isothermal-LCF conditions correlated with the fatigue J-integral range; the shaded band indicates the fatigue crack growth curve of physically long crack obtained by using CT and CCT specimens in Ref. [5]. 
It can be also found in Fig. 3 that the fatigue crack growth rate under the isothermal LCF loading depends on the test temperature; the growth rates at $650^{\circ} \mathrm{C}$ where the crack exhibits the intergranular propagation mode (CC1 and CC2) are higher than those at $470^{\circ} \mathrm{C}$ of which the crack growth modes is transgranular (PP). However, the strain rate dependence on the crack growth rate at $650^{\circ} \mathrm{C}$ is negligible. The crack growth rate at $650^{\circ} \mathrm{C}$ might be accelerated by the creep effect. When the $316 \mathrm{FR}$ is subjected to the creep superimposed fatigue loading, so-called creep-fatigue loading, the creep damages such as cavity nucleation and growth, which are accumulated at the grain boundaries perpendicular to the loading axis, cause the intergranular failure [23]. However, the crack propagates by transgranular mode under pure fatigue condition [24]. Empirically, it is well known that the crack growth rate under the creep-fatigue condition can be estimated by the linear summation law consisting of fatigue and creep terms as follows [25, 26]:

$$
\frac{d a}{d N}=\left(\frac{d a}{d N}\right)_{\text {fatigue }}+\left(\frac{d a}{d N}\right)_{\text {creep }}=C_{f} \Delta J_{f}^{m_{f}}+C_{c} \Delta J_{c}^{m_{c}}
$$

where $C_{\mathrm{f}}, m_{\mathrm{f}}, C_{\mathrm{c}}$ and $m_{\mathrm{c}}$ are fatigue and creep material constants, respectively, $\Delta J_{\mathrm{c}}$ is the creep J-integral range, evaluated from following equation for surface short crack [27];

$$
\Delta J_{c}=F^{2} f\left(n_{c}\right) \sigma_{\max } \Delta \varepsilon_{c} a
$$

where $\sigma_{\max }$ is the maximum stress in each cycle, $n_{\mathrm{c}}$ is the creep exponent, and $\Delta \varepsilon_{\mathrm{c}}$ is the creep strain range. $F$ and $f\left(n_{\mathrm{c}}\right)$ are obtained by means of Eq. (2). $\Delta \varepsilon_{\mathrm{c}}$ can be evaluated from the comparison between the hysteresis loop of creep-fatigue condition and that of fatigue dominant one as shown in Fig. 4. It was reviled from the cyclic deformation tests at the various strain rates that the creep deformation was negligible when the strain rate was higher than $0.1 \% / \mathrm{s}$. Therefore, the hysteresis loop of fatigue dominant condition was obtained at $0.1 \% / \mathrm{s}$ in this study.

Fig. 5 shows the comparison between the crack growth rate predicted by using Eq. (3) and the experimental data for CC1 and CC2. In the prediction, $C_{\mathrm{f}}$ and $m_{\mathrm{f}}$ of fatigue terms are obtained from the experimental data under PP condition, and $C_{\mathrm{c}}$ and $m_{\mathrm{c}}$ of creep terms are obtained from the static creep crack growth test reported in Ref. [28]. As shown in Fig. 5, the crack growth rates are overestimated when the predictions are made by using Eq. (3). Takahashi et al. also reported that the static creep crack showed higher growth rates compared with the creep-fatigue one in 316 FR [29].

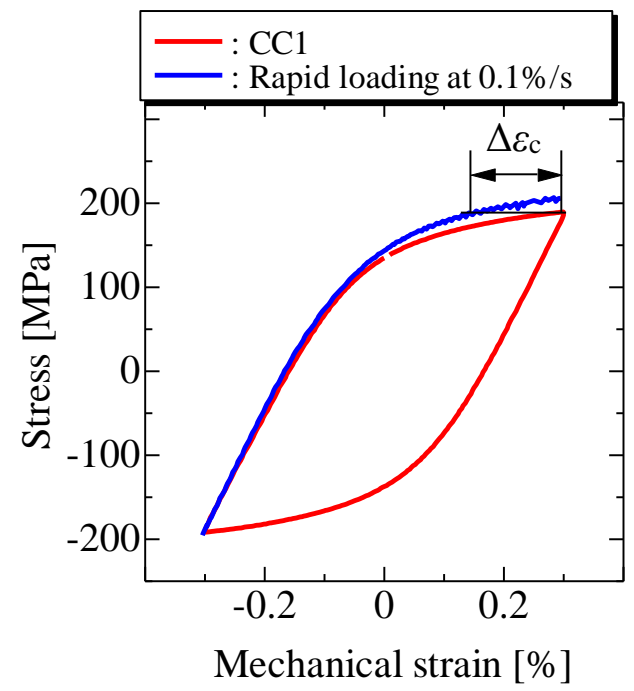

Figure 4: Evaluation of the creep strain range from hysteresis loops.

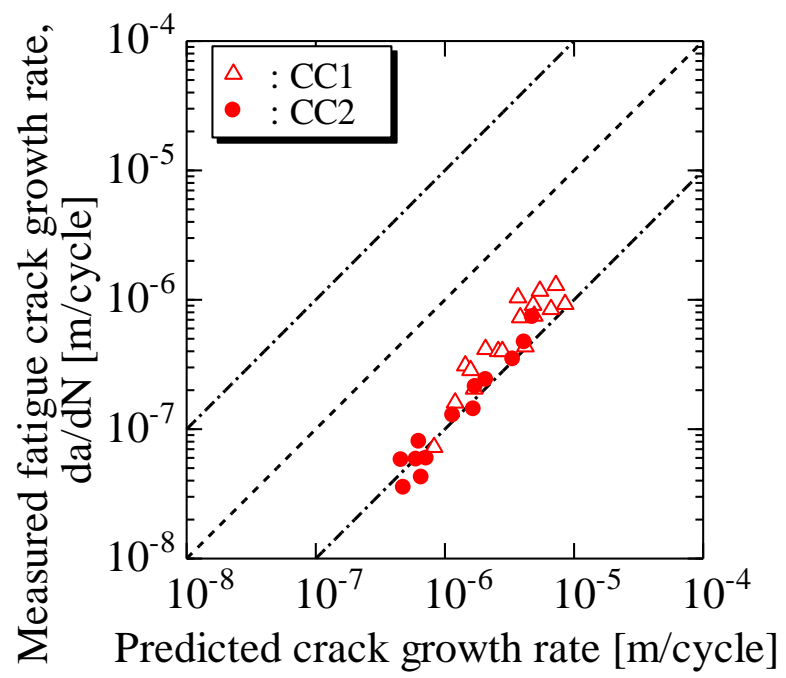

Figure 5: Comparison between the predicted (see Eq. (3)) and the measured crack propagation rate for isothermal LCF tests at $650^{\circ} \mathrm{C}$; the dashed lines indicate the range of a factor of 10 .

Fig. 6 shows the fatigue crack growth behaviors under the TMF conditions as a function of $\Delta J_{\mathrm{f}}$ evaluated by Eq. (1), where $n_{\mathrm{f}}$ for TMF loadings is 0.426 . In Fig. 6 , the $\Delta J_{\mathrm{f}}$ for IPC02, IPC04 was calculated by using Eq. (1) with $\Delta \sigma, \Delta \varepsilon_{\mathrm{e}}$ and $\Delta \varepsilon_{\mathrm{p}}$ evaluated from the main TMF hysteresis loop. In this paper, the fatigue crack growth rate for the combined TMF and LCF loadings (IPC02 and IPC04) is defined by crack growth rate per main TMF cycle. For comparison, the fatigue crack 
growth curves related to the isothermal LCF loading are also shown in Fig. 6. As shown in Fig. 6, scatters of data points are relatively large. However, it can be found that the fatigue crack growth rate under IP condition is almost comparable to those under CC1 and CC2 conditions. Also, the growth rate under OP condition is nearly the same of PP condition. It can be concluded from these results that the fatigue crack growth rate under simple TMF condition can be estimated from the fatigue crack growth curve under the isothermal LCF condition, taking into account the crack propagation path even if the thermal cycle is applied synchronizing with the strain cycle.

It is found in Fig. 6 that the growth rate is accelerated by superimposing of the isothermal LCF loading to the main cycle of TMF loading. The effect of such a superimposing on the fatigue crack growth rate will be discussed in the next section.

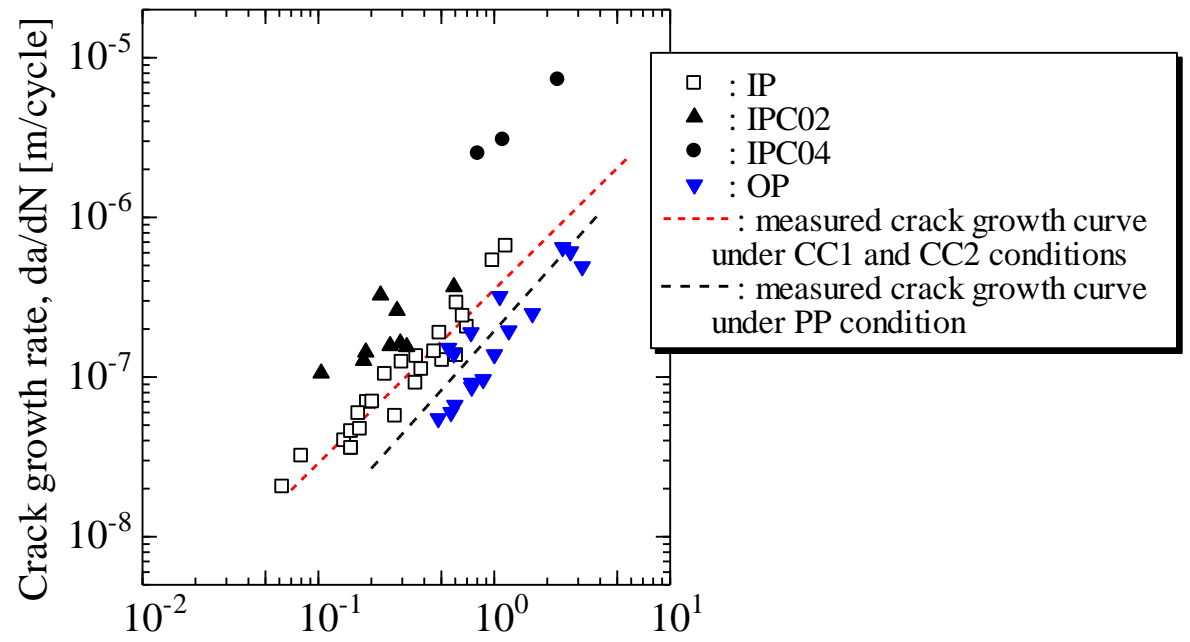

Fatigue $\mathrm{J}$-integral range, $\Delta \mathrm{J}_{\mathrm{f}}[\mathrm{kN} / \mathrm{m}]$

Figure 6: Fatigue crack growth rates under TMF and combined TMF and LCF conditions correlated with the fatigue J-integral range.

\section{Estimation of crack growth rate under simple TMF and combined TMF-LCF conditions}

As shown in Fig. 5, the crack growth rates under CC1 and CC2 conditions were overestimated when the predictions are made by using the linear summation law, Eq. (3). In the case of TMF cracks, it is more difficult to apply the summation law because the loading rate of the TMF test can not be increased sufficiently due to the limitation of the heating rate synchronizing with the strain rate. Therefore, in this study, the crack growth rates are correlated with the fatigue J-integral range, $\Delta J_{\mathrm{f}}$, taking into account the crack growth modes. From Fig. 3, the following equations may be employed to express the growth rate for the transgranular crack-propagation (PP) or the intergranular one (CC1 and CC2):

$$
\frac{d a}{d N}=C_{f} \Delta J_{f}^{m_{f}}=\left\{\begin{array}{l}
1.94 \times 10^{-7} \Delta J_{f}^{1.23} \text { for the transgranular crack propagation } \\
3.54 \times 10^{-7} \Delta J_{f}^{1.09} \text { for the intergranular crack propagation }
\end{array}\right.
$$

It is also revealed from Fig.6 that Eq. (5) is applicable to the fatigue crack which propagates under OP and IP TMF conditions.

The fatigue crack growth rates under combined TMF and LCF conditions are predicted according to the following summation law:

$$
\frac{d a}{d N}=\left(\frac{d a}{d N}\right)_{\text {main TMF grde }}+\left(\frac{d a}{d N}\right)_{\text {sub LCF grde }}=C_{f}\left(\Delta J_{f, \text { main }}\right)^{m_{f}}+N_{s u b} C_{f}\left(\Delta J_{f, s u b}\right)^{m_{f}}
$$

where $\Delta J_{\mathrm{f} \text {,main }}$ and $\Delta J_{\mathrm{f} \text {,sub }}$ are the fatigue J-integral range for the main-TMF cycle and the sub-LCF cycle, respectively, and $N_{\text {sub }}$ is the number of sub LCF cycle per main TMF cycle $\left(N_{\text {sub }}=10\right.$ cycles in this study). The material constants $C_{\mathrm{f}}$ and $m_{\mathrm{f}}$ are the experimental values depending on the crack propagation modes (see Eq. (5)). The prediction results for the combined TMF-LCF loadings as well as for the TMF loadings are shown in Fig. 7. It is revealed in Fig. 7 that the fatigue crack growth rate under the above test conditions can be predicted by using Eqs. (5) and (6) according to the crack propagation modes. 


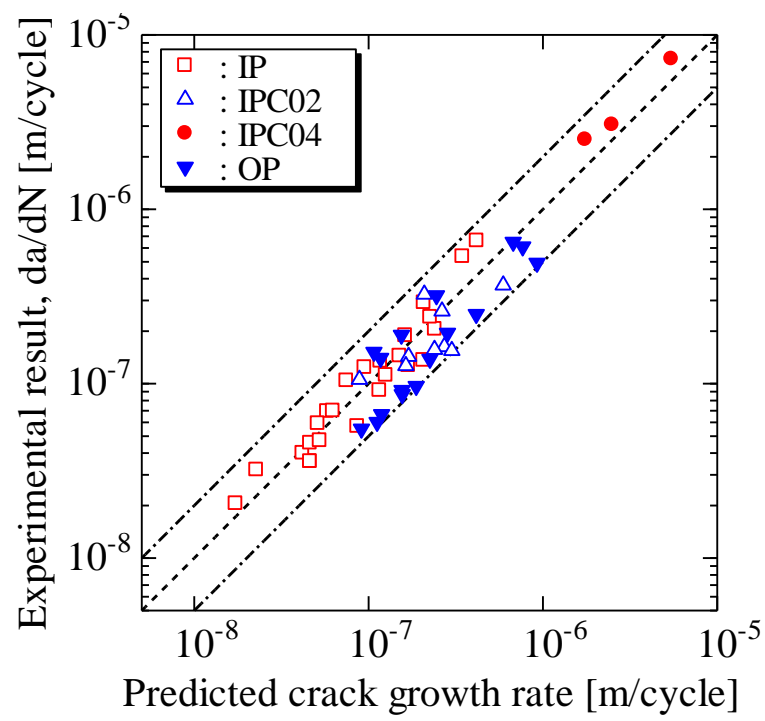

Figure 7: Comparison between the predicted (see Eq. (5) and (6)) and the measured crack propagation rate for TMF and combined TMF and LCF tests; the dashed lines indicate the range of a factor of 2.

\section{CONCLUSIONS}

I $\mathrm{n}$ this paper, the effect of superimposing of sub-cycles under isothermal Low Cycle Fatigue (LCF) loading to a main cycle under thermomechanical fatigue (TMF) loading on the crack propagation behavior of 316FR stainless steel was investigated. The main conclusions obtained are summarized as follows.

1) The stress range of main TMF cycle was affected by the superimposition of sub-cycles of LCF; the stress range for the combined TMF and LCF loading was decreased compared with that for the pure TMF condition at the given strain range. 2) The crack propagation path depends on the loading condition. Under the isothermal LCF loading at high temperature and in-phase TMF loading (where the tensile loading is applied at high temperature) the cracks appear to be initiated and propagated at grain boundary perpendicular to the loading axis. On the other hand, under the isothermal LCF loading at the middle temperature and the out-of-phase TMF loading (where the tensile loading is applied at low temperature) the cracks initiated and propagated by means of the transgranular mode.

3) The fatigue crack growth rate was accelerated by superimposing of the isothermal LCF loading to the TMF loading. The crack growth rates could be predicted according to the summation law of crack growth behavior based on the Jintegral approach, according to the crack propagation path.

\section{REFERENCES}

[1] Miura, N., Nakayama, Y., Takahashi, Y., (2002). Development of flaw evaluation guideline for FBR component, Nuclear Eng. and Design, 212, pp. 13-19.

[2] Nakazawa, T., Kimura, H., Kimura, K., Kaguchi, K. (2003). Advanced Type Stainless 316FR for Fast Breeder Reactor Structures, J. of Mat. Processing Tech., 143-144, pp. 905-909.

[3] Ekaputra, I.M., Kim, W.G., Park, J-Y., Kim, E-S. (2016). Characterization of the Q* parameter for evaluation creep crack growth rate for type 316LN stainless steel, J. of Mech. Sci. and Tech., 30, pp. 3151-3158.

[4] Takahashi, Y., Shibamoto, H., Inoue, K. (2008). Long-Term Creep Rupture Behavior of Smoothed and Notched Bar Specimens of Low-Carbon Nitrogen-Controlled 316 Stainless Steel (316FR) and Their Evaluation, Nuclear Eng. and Design, 238, pp. 310-321.

[5] Fujioka, T., Shimakawa, T., Miura, N., Kashima, K. (1995). Development and verification of an evaluation method for creep-fatigue crack propagation in FBR components, ASME PVP, 305, pp. 395-402.

[6] Ueta, M., Nishida, T., Koto, H., Sukekawa, M., Taguchi, K. (1995). Creep-Fatigue Properties of Advanced 316-Steel for FBR Structures, ASME PVP, 313, pp. 423-428. 
[7] Okazaki, M., Yamazaki, Y. (1999). Creep-fatigue small crack propagation in a single crystal Ni-base superalloy, CMSX-2: Microstructural influences and environmental effects, Int. J. of Fatigue 21, pp. S79-S86

[8] Yoshihisa, E., Raman, S.G.S. (2000). Thermomechanical and isothermal fatigue behavior of type 316 stainless steel base metal, weld metal, and joint, Sci. and Tech. of Welding and Joining, 5, pp. 174-182.

[9] Takahashi, Y., Shibamoto, H., Inoue, K. (2008). Study on Creep-Fatigue Life Prediction Methods for Low-Carbon Nitrogen-Controlled 316 Stainless Steel (316FR), Nuclear Eng. and Design, 238, pp. 322-335.

[10] Samuel, K.G., Sasikala, G., Ray, S.K. (2011). On R ration dependence of threshold stress intensity factor range for fatigue crack growth in type 316(N) stainless steel, Mat. Sci. and Tech., 27, pp. 371-376.

[11] Babu, M.N., Dutt, B.S., Venugopal, S., Sasikara, G., Albert, S.K., Bhaduri, A.K. Jayakumar, T. (2013). Fatigue crack growth behavior 316LN stainless steel with different nitrogen contents, Procedia Eng., 55, pp. 716-721.

[12] Hormozi, R., Biglari, F., Nikbin, K. (2015). Experimental and numerical creep-fatigue study of Type 316 stainless steel failure under high temperature LCF loading condition with different hold time, Eng. Fracture Mech., 141, pp. 19-43.

[13] Buss, T.M., Hyde, C.J. (2015). Cyclic thermomechanical testing of 316 stainless steel, Mat. at High Temp. 32, pp. 276279.

[14] Prasad Reddy, G.V., Nagesha, A. (2017). Kannan, R., Sandhya, R., Laha, K., Thermomechanical fatigue behavior of nitrogen enhanced 316LN stainless steel: effect of cyclic strain, Int. J. Fatigue, 103, pp. 176-184.

[15]Zhao, L., Xu, L., Nikbin, K. (2017). Predicting failure modes in creep and creep-fatigue crack growth using random grain/grain boundary idealized microstructure meshing system, Mat. Sci. \& Eng. A, 704, pp. 274-286

[16] Metzger, M., Nieweg, B., Schweizer, C., Seifert, T. (2013). Lifetime prediction of cast iron materials under combined thermomechanical fatigue and high cycle fatigue loading using a mechanism-based model, Int. J. of Fatigue, 53, pp. 58-66.

[17] Hormozi, R., Biglari, F., Nikbin, K. (2015). Experimental study of type 316 stainless steel failure under LCF/TMF loading conditions, Int. J. of Fatigue, 75, pp. 153-169.

[18] Norman, V., Skoglund, P., Leidermark, D., Moverare, K. (2016). The effect of superimposed high-cycle fatigue on thermo-mechanical fatigue in cast iron, Int. J. of Fatigue, 88, pp. 121-131.

[19] Fedelich, B., Kühn, H.-J., Rehmer, B. Skrotzki, B. (2016). Modeling the lifetime reduction due to the superposition of TMF and HCF loadings in cast iron alloys, Procedia Structural Integrity, 2, pp. 2190-2197.

[20] Sarkr, A., Nagasha, A., Parameswaran, P. Sandhya, R., Laha, K., Okazaki, M. (2017). Evolution of damage under combined low and high cycle fatigue loading in a type $316 \mathrm{LN}$ stainless steel at different temperatures, Int. J. of Fatigue, 103 28-38.

[21] Shih, C.F., Hutchinson, J.W. (1976), Fully plastic solutions and large scale yielding estimates for plane stress crack problems, J. of Eng. Mat. and Tech., 98, pp. 289-295.

[22] Dowling, N.E. (1977). Crack growth during low-cycle fatigue of smooth axial specimens, cyclic stress-strain and plastic deformation aspects of fatigue crack growth, ASTM STP, 637, pp. 97-121.

[23] Wada, Y., Aoto, K. Ueno, F. (1997). Creep-fatigue evaluation method for type 304 and 316FR SS, International Atomic Energy Agency, 282, pp. 75-86.

[24] Kato, S., Furukawa, T., Yoshida, E. (2010) High-cycle fatigue properties of FBR grade type 316ss at elevated temperatures, JAEA-Research-2010-022. DOI: 10.11484/JAEA-Research-2010-022 (in Japanese).

[25] Taira, S., Ohtani, R., Kitamura, T., Yamada, K. (1979). J-Integral Approach to Crack Propagation under Combined Creep and Fatigue Condition, J. Soc. Mat. Sci., Japan, 28, pp. 414-420 (in Japanese).

[26] Ohtani, R., Kitamura, T., Abe, M., Kuriyama, Y., Miki (1990). H., Surface small crack initiation and growth of heat resisting alloys in creep-fatigue, J. Soc. of Mat. Sci., Japan, pp.529-535 (in Japanese).

[27] Ohtani, R., Kitamura (1985). On the fatigue life law for smooth specimens at elevated temperatures derived from fracture mechanics law of crack propagation, J. Soc. of Mat. Sci., Japan, pp.843-849 (in Japanese).

[28] Koto, H., Kaneko, H., Takanabe, K., Wada, Y. (1989). Creep-fatigue strength of modified 316 steel, Proc. of the 27th Symposium on Strength of Materials at High Temperatures, Soc. of Mat. Sci., Japan, pp. 51-55 (in Japanese).

[29] Takahashi, H., Uno, T., Tanaka, K. (2000). Evaluation of creep-fatigue crack propagation for 316FR stainless steel welded joints, J. Soc. Mat. Sci., Japan, 49, pp. 322-326 (in Japanese). 